\title{
sciendo
}

DOI: $10.2478 /$ rjp-2019-0023

Rom J Psychoanal 2019, 12(2):153-158

Rom J Psychoanal

\section{BITTER MOON. BRIEF PSYCHOANALYTICAL REFLEXIONS ON A DETAIL}

Alice Popescu ${ }^{14}$

\begin{abstract}
The majority of book-to-film adaptations operate more or less important adjustments on the initial text. In this respect, the present article attempts to investigate the psychoanalytical relevance of such a textual intervention in Roman Polanski's 1992 film, "Bitter Moon", based on Pascal Bruckner's novel, "Lunes de fiel" (1981). The analysis takes the Freudian theories on sadomasochism and death instinct as a starting point.
\end{abstract}

Keywords: Bitter Moon, sadomasochism, death instinct, sublimation, omnipotence, narcissism of minor differences

\section{Introduction}

The Moon, ancient symbol of femininity and fertility, of human emotions, and their energetics, is the object of complex references in literature, cinematography and arts in general. Nevertheless, it is not our intention to dwell here on the many cultural significances it carries, but rather to focus on its relevance in a particular context, that of the cinematographic adaptation of one of the most famous and controversial books of the eighties.

\footnotetext{
${ }^{14}$ Titu Maiorescu University, Faculty of Psychology; alivpopescu@yahoo.com
} 
In spite of the passage of time, Roman Polanski's Bitter Moon (1992), the film based on Pascal Bruckner's 1981 book, Lunes de Fiel, continues to offer a vast material for the study of the contemporary couple, one more reason for us not to get lost in the complexity of the topic, but rather to clearly state what our article is not about: it is not about the entirety of the movie (or of the novel, for that matter), nor it is interested in exhausting their many and intricate connections to psychoanalysis. "Why psychoanalysis?" one might ask... The answer resides in the oddity of the characters' behavior, otherwise resistant to the honest language of transparent motivations and raţional thinking. And why not focusing on the novel as a whole? Because our attention has rather been drawn by a small detail or a change occured in the process of turning the book into a movie...

The film presents the drama of a modern couple (Franz and Rebecca in the book / Oscar and Mimi in the movie) that breaches the limits of normality, transforming love into hatred and life into death. Both the film and the novel are conceived as a frame story (a story within another story): Oscar, a paralytic husband, narrates the tale of his marriage, forcing young Nigel into becoming his confident. On the occasion of their wedding anniversary, Nigel and his wife, Fiona, decide to embark on a cruise ship heading to India. But their seven year loving relationship will soon be put to the test by the less ordinary encounter with the strange couple. In a way, Nigel and Fiona represent the opposites of Oscar and Mimi, inasmuch as the lunar phase known in astronomy as "the new moon" opposes "the full moon". It is not by chance that the Moon gives the title of the film: as a representation of the natural feminine force of creation, it stands for one of the closest synonyms to life. Though Polanski's film, as well as Bruckner's book, are everything but a celebration of life...

\section{The Bitterer the Moon, the Longer the Eternity}

Bitter Moon is the story of the passionate infatuation of an American man in his forties for a young French girl met on a bus in Paris. For him, "eternity" begins on that particular autumn day, as he says (BRUCKNER, 1981, p.17), and the word is significant beyond expectation. Although we seem to witness the degradation of a romantic love affair into scatology, sadomasochism and the death of the two protagonists, there isn't, in fact, a real "evolution" of the relation. The key to the events doesn't lie in the passage of time, as one might suspect, but in the "timeless" dimension of the unconscious. This is "the eternity" that Oscar 
intuitively refers to in the first sentence of the movie (as well as of the book), while the entangled life and death instincts unfold together, disguised in an apparent developing plot.

In 1905, in Three Essays on the Theory of Sexuality, Freud approaches the terms "sadism" and "masochism" for the first time, classifying them among the deviations of human sexual behavior. For him, a sadist is simultaneously a masochist (Freud, 1905, pp. 80-81). It is only in Beyond the Pleasure Principle (1920) that he will finally link sadomasochism to the existence of a death instinct (Todestriebe or death drives, in the original text).

Bitter Moon seems to be a wonderful literary exemplification of Freud's late theory on destructive drives, accurately illustrating it at play in the dysfunctional couple formed by Oscar and Mimi. For the man, the Moon turns bitter when he starts to feel bored in bed. As a result, sadomasochistic sex games take the place of the deceased passion, and, later on, betrayal and constant humiliation of the partner continue the process. Finally, when nothing else works, the cruelest abandonment becomes the last resort. After having forced her into having an abortion, Oscar cowardly dumps Mimi on a flight to an exotic destination where the two of them were supposed to spend the holiday together. Through the window of the plane we can see the moon... a bitter one, deprived of all meaning, a metaphor for the woman who has just lost her unborn child. The abortion, the abandonment, and all the psychological baggage left behind by this destructive relation will lead Mimi to a turning point in her life.

\section{Changing Roles. Till Death Instinct Do Us Part}

One might think that after all the torment endured, she will want to never cross paths with Oscar again. But, then, one would be mistaken: Mimi comes back to cripple him from the waist down (a life sentence) and to subsequently marry and nurse him till death do them part. We have now sufficient reasons to consider this out of the ordinary marriage an almighty "sadomasochistic contract" that has been there from the very moment of their accidental encounter, and will never expire. Although a change in their relationship does occur: the role reversal. Indeed, Mimi will take complete control of her husband, making his life a living hell, as he previously did to her.

Again, the two protagonists will change roles one last time: before the cruise is over, Oscar shoots his wife and then kills himself, a gesture of supreme and undeniable power that 
will bring about the fulfillment of the death instinct to completion. In the Freudian key to the story we are led to the conclusion that the two characters, for some reason unwilling or unable to sublimate both their sexual and aggressive drives, end by exhausting their "credit" (as Oscar suggestively puts it) and completely deliver themselves to destructiveness.

But Jack and Kerry Kelly Novick's study on sadomasochism (Novick et all, 2002, pp.11331155) sheds a new and interesting light on the matter. According to the Novicks, sadomasochistic drives cannot be sublimated, as their long term research on subjects suffering from this condition have already proved. All the more, and contrary to Freud's findings, they accompany (and may even evolve during) each of the psychosexual stages in one's childhood and - most importantly - are intimately related to a feeling of omnipotence, not necessarily the one attached to the primary narcissism. The results of their study have drawn our attention in respect to one of the slight modifications that Roman Polanski operates on the original version of Bruckner's story. We have noticed that the male character (Franz) is, in the book, a very successful and active doctor who often participates in congresses away from home, while Oscar (in the movie) seems to lead a very static, unfulfilled professional life. He has inherited a fortune that allows him to live decently out of a monthly income and to focus on writing a novel instead, but, unfortunately, his work is constantly rejected by editors. This particular detail has led us to think that, according to the Freudian perspective regarding the aggressive tendencies inhibited in their aim (on which power over nature and, consequently, social accomplishments are grounded) would more adequately advocate for Bruckner's choice regarding Franz's professional status. As Freud argues in "Civilization and Its Discontents", the death instinct, "even when it shows itself without any sexual purpose, even in the blindest frenzy of destructiveness, one cannot ignore the fact that satisfaction of it is accompanied by an extraordinarily intense narcissistic enjoyment, due to the fulfilment it brings to the ego of its oldest omnipotence-wishes." But "even when it emerges without any sexual purpose, in the blindest fury of destructiveness, we cannot fail to recognize that the satisfaction of the instinct is accompanied by an extraordinarily high degree of narcissistic enjoyment, owing to its presenting the ego with a fulfilment of the latter's old wishes for omnipotence. The instinct of destruction, moderated and tamed, and, as it were, inhibited in its aim, must, when it is directed towards objects, provide the ego with the satisfaction of its vital needs and with control over nature." (FREUD, 1930, p. 121). On the contrary, unable to "temper" and "harness" (or, in other words, to sublimate) his death instinct into a professional activity able to provide him with a feeling of social accomplishment, the male character in the movie seems to be the best 
candidate for the position from Novicks' perspective. Unlike Franz in the book, who, by all appearances, is a successful, active doctor (he goes to a Congress of Parasitology), Oscar and also Mimi (previously a hairdresser) don't seem to have accomplished anything meritorious in life, their social profile placing them among the marginal. Though Mimi's level of awareness and, consequently, of unsatisfaction regarding her social condition remains unclear, Oscar's efforts to succeed and their constant failure might indicate an important potential for frustration fueled actions. In other words, if we were to consider Freud's approach on the matter, in neither of the two cases (Oscar and Mimi) the sublimation of the aggressive tendencies for the social benefit is at work, the sadomasochistic prototype in the Novicks' discoveries fitting them better. The couple draws its satisfaction from their ego feelings of omnipotence, source of an "intense narcissistic enjoyment", as Freud puts it, as well as from acting out their sexual fantasies through increasingly degrading sadomasochistic practices. Not being provided with sufficient, exact data about the previous psychosexual development of the two characters (both in the movie and in the book), nor about their previous sexual histories, we might assume that the sadomasochistic fantasies acted out in the relation have been revealed, put into practice and brought to the climax only within the specific psychological conditions of their particular couple. Also, the scarcity of information on the topic (although we know that they have been in other relationships before and that Franz/ Oscar has a child from a two year marriage) neither favors, nor confirms Freud's theory concerning the sadomasochistic behavior seen as a regression to the anal stage. In what concerns the Novicks' view, advocating for the presence of the sadomasochistic drives at all stages of the sexual development, the situation is similar. But the micturition practices (specific to the urethral stage) experimented by the two protagonists prior to the anal ones, might incline the balance to the Freudian approach, since the scatological games coincide with the point of no return for their relation.

From a different standpoint, the literary version of the couple confirms Freud's visionary considerations about what he called "the narcissism of minor differences" between groups, "through which cohesion amongst the members of a group is made easier" (FREUD, 1930, p. 788). Due to their peculiar sexual practices, Franz and Rebecca start to feel different from other couples, and to experience a sense of pride (BRUCKNER, 1981, p. 83) and contempt for ordinary lovers, by considering themselves far ahead of their times, close to the sublime... (BRUCKNER, 1981, p. 92). Unfortunately, this narcissism of minor differences will add a new brick to their fated union. 


\section{Conclusions}

In the light of the results of the study conducted by Jack and Kerry Kelly Novick, Roman Polanski's option for a marginal social status of the male character in Bitter Moon seems to offer more insight about the dynamics at play in the tragic denouement of the couple and, consequently, about the "bitterness" of the Moon itself. Perhaps the fated incapacity for instinctual sublimation makes the emotional alchemy frozen in an eternal frustration and, eventually, die...

The history of book-to-film adaptations gives account of outcomes that sometimes go almost unnoticed, as well as of others overshadowing the original literary text. In the fortunate case of Polanski's adaptation of Pascal Bruckner's book, both literature and cinematography are priviledged. From a general perspective and with no regard to their artistic value, sometimes slight differences between texts and film scenarios speak volumes. Could a late adaptation of a book to a movie be an unconscious expression of the gain in the cultural paradigm at a particular time? Or, even more audaciously, could it be in tune with or sensitive to the slightest future research advancement on the way? If so, Bitter Moon would be an exemplification of such a successful calibration. In the same logic, studies containing interpretations (in our case, a brief psychoanalytical attempt) of the phenomenon might run the same risk of bias or, on the contrary, they might have the chance to notice new possible shades due to the new "glasses".

\section{REFERENCES}

BRUCKNER, P. (1981). Luni de fiere [Bitter Moon], Babel, Bucharest, 1991, p. 83, p. 92 (Lunes de fiel, Seuil, Paris).

FREUD, S. (1905). Trei studii privind teoria sexualității [Three Essays on the Theory of Sexuality], Psihanaliză și sexualitate, Ed. Științifică, Bucharest, 1994, pp. 80 - 81. (Drei Abhandlungen zur Sexualtheorie. Fischer: Frankfurt am Main).

FREUD, S. (1930). Civilization and its Discontents, The Standard Edition of the Complete Psychological Works of Sigmund Freud, Volume XXI (1927-1931): The Future of an Illusion, Civilization and Its Discontents, and Other Works, 56-147, (p. 121).

NOVICK, J., NOVICK, K.K. (2002). Une théorie développementale du sadomasochisme, [A Developmental Theory of Sadomasochism], Revue française de psychanalyse, Presses Universitaires de France, 2002/4 (66), pp. 1133 - 1155. 